Terbit online pada laman web jurnal: http://journal.isas.or.id/index.php/JASENS

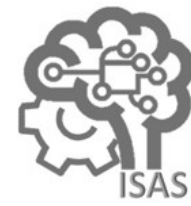

JOURNAL OF APPLIED SMART ELECTRICAL

NETWORK AND SYSTEMS (JASENS)

Vol. 2 No. 2 (2021) 43 - 48

ISSN Media Elektronik: 2723-5467

\title{
Implementasi Kontroler PI Pada Buck Converter Sebagai Pengaturan Tegangan Konstan Di Sistem Turbin Angin Permanent Magnet Schronous Generator (PMSG) Dilengkapi Sistem Monitoring Berbasis IoT
}

\author{
Muhammad Zainal Arifin ${ }^{1}$, Ratna Ika Putri ${ }^{2}$ \\ ${ }^{1,2}$ Teknik Elektronika, Teknik Elektro, Politeknik Negeri Malang \\ ${ }^{1}$ nozaaqbar@gmail.com*,2ratna.ika@polinema.ac.id
}

\begin{abstract}
The need for electrical energy has become a primary need for humans, until now the energy used to generate electrical energy is fossil fuels whose numbers are dwindling. Renewal of energy is needed through renewable energy, namely using unlimited wind energy. The wind speed is always changing in a fluctuating manner which can affect the output voltage at the power plant. In this study, the wind turbine used is a permanent magnet synchronous generator, the output voltage from the generator is a 3-phase electric voltage which is then rectified into a DC voltage. To be able to stabilize the voltage, a buck converter circuit is used as a voltage reducer, the switching control used in the buck converter uses a half bridge with IC IR2110 with a frequency of $31.5 \mathrm{kHz}$. The buck converter can reduce the voltage with an input voltage range of 30-100 Volts with a duty cycle of 10$90 \%$, the PI control system on the buck converter circuit for constant voltage regulation of 27 Volts (settpoint) and using the IoT thingspeak website for remote monitoring.
\end{abstract}

Keywords: Permanent Magnet Synchronous Generator, Buck Converter, Kontrol PI, Thinkspeak.

\begin{abstract}
Abstrak
Kebutuhan energi listrik telah menjadi kebutuhan primer bagi manusia, hingga saat ini energi yang digunakan pembangkit energi listrik adalah bahan bakar dari fosil yang jumlahnya semakin menipis. Dibutuhkan pembaharuan energi melalui energi terbarukan yaitu menggunakan energi angin yang jumlahnya tidak terbatas. Kecepatan angin selalu berubah secara fluktuasi yang dapat mempengaruhi keluaran tegangan pada pembangkit energi listrik. Pada penelitian ini turbin angin yang digunakan yaitu permanent magnet synchronous generator, keluaran tegangan listrik dari generator adalah tegangan listrik 3 phase yang kemudian disearahkan menjadi tegangan DC. Untuk dapat menstabilkan tegangan digunakan rangkaian buck converter sebagai penurun tegangan, kontrol switching yang digunakan pada buck converter menggunakan half bridge dengan IC IR2110 frekuensi 31,5 kHz. Buck converter dapat menurunkan tegangan dengan range tegangan input 30-100 Volt dengan duty sycle 10-90\%, sistem kontrol PI pada rangkaian buck converter untuk pengaturan tegangan konstan yaitu 27 Volt (settpoint) serta menggunakan website IoT thingspeak untuk monitoring jarak jauh.
\end{abstract}

Kata kunci: Permanent Magnet Synchronous Generator, Buck Converter, Kontrol PI, Thinkspeak.

Diterima Redaksi : 24-06-2021 | Selesai Revisi : 16-07-2021 | Diterbitkan Online : 31-12-2021

\section{Pendahuluan}

Pemanfaatan sumber energi baru dan terbarukan yang berwawasan lingkungan merupakan upaya untuk mengurangi polusi serta menghemat sumber daya minyak bumi[1]. Pemanfaatan energi angin di Indonesia diarahkan untuk mencukupi listrik di pedesaan dan berkontribusi sebagai energi altematif di masa mendatang[2]. Hingga saat ini penggunaan turbin angin sangat dimungkinkan, nantinya daya yang dihasilkan oleh turbin angin akan di simpan ke dalam baterai (ACCU)[3]. Terdapat beberapa jenis turbin angin yaitu diantaranya turbin angin sumbu horizontal dan turbin angin sumbu vertical[4]. PMSG (Permanent Magnet Syncyronous Generator) merupakan komponen utama pembangkit listrik tenaga angin, PMSG merubah energi gerak menjadi energi listrik[5]. Daya yang dihasilkan oleh generator PMSG tidak selalu stabil tergantung angin sebagai penggerak[6], sedangkan untuk melakukan pengisian baterai diperlukan tegangan yang stabil maka dari itu digunakanlah rangkaian buck converter sebagai penurun tegangan DC menjadi tegangan DC yang lebih rendah dari masukan[7]. Buck converter merupakan salah satu jenis DC chopper yang memiliki fungsi menstabilkan tegangan dengan menurunkan tegangan dimana tegangan keluaran lebih 
rendah dari tegangan masukan tanpa harus menghilangkan daya yang relatif besar[8]. Untuk mendapatkan tegangan stabil maka dibutukan suatu kontroler salah satu control yaitu control PI yang dapat digunakan untuk mengatur tegangan keluaran dengan cara mangatur duty cycle dan mengoreksi error yang berasal dari hasil feedback, sehingga tegangan keluaran stabil[9]. Hasil tegangan keluaran akan ditampilkan di dashboard Thingspeak atau aplikasi mobile dengan menggunakan IoT (Internet of Things)[10].

\section{Metode Penelitian}

\subsection{Diagram Blok}

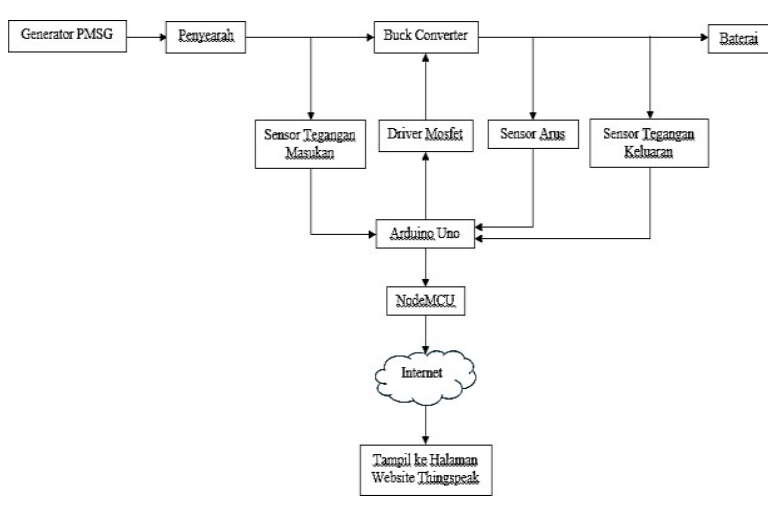

Gambar 1. Diagram Blok

Tegangan dari ganerator akan masuk menuju rangkaian penyearah (three phase rectifier) tidak terkendali dan filter untuk merubah tegangan menjadi tegangan DC. Batas tegangan yang akan diproses $30-100$ Volt, jika tegangan kurang dari atau lebih dari batas maka relay akan memutus. Tegangan yang telah disearahkan dalam batas 30-100 volt akan masuk menuju rangkaian Buck converter. Buck converter menggunakan sistem close loop serta sensor tegangan sebagai feedback. Pada rangkaian Buck Converter tegangan akan diturunkan sehingga menghasilkan tegangan DC dengan nilai 27 volt. Sensor tegangan output pada rangkaian mendeteksi tegangan serta mengirimkan sinyal ke NodeMCU untuk dapat dimonitoring melalui website IoT Thingspeak.

\subsection{Perancangan Sensor Tegangan}

Gambar 2 merupakan perancangan rangkaian sensor tegangan menggunakan sistem pembagi tegangan dengan dua resistor seri untuk mengkonversi tegangan maksimal 200 Volt menjadi tegangan 5 Volt sehingga dapat dibaca oleh pin ADC mikrokontroler.

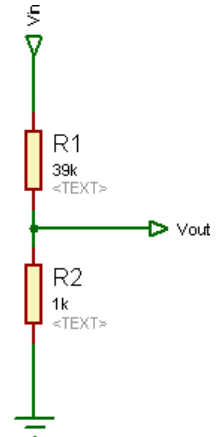

Gambar 2. Rangkaian Sensor Tegangan

Untuk mengetahui besaran komponen yang digunakan R1 dan R2 pada rangkaian sensor tegangan maka dapat menggunakan persamaan yaitu :

Perhitungan Arus Maksimal Pada Beban Resistor

$I_{\max }=\frac{p}{V \max }$

$l_{\max }=5 \mathrm{~mA}$

Perhitungan Nilai Resistansi Total Kedua Resistor

$$
\begin{aligned}
& \text { Rtotal } \text { min }_{\text {min }}=\frac{V \max }{l_{\max }} \\
& \text { Rtotalmin }_{\text {ma }}=40 \mathrm{k} \Omega
\end{aligned}
$$

Perhitungan Nilai Resistansi R1 dan R2

$$
\begin{aligned}
& \frac{5}{200}=R \mathbf{1} 40 k \\
& R \mathbf{1}=\mathbf{1} \mathrm{k} \Omega \\
& R \text { total }=R \mathbf{1}+R \mathbf{2} \\
& 40 k=\mathbf{1} k+R \mathbf{2} \\
& R \mathbf{2}=39 k
\end{aligned}
$$

\subsection{Perancangan Modul Sensor Arus}

Gambar 3 merupakan sensor arus ACS712 dapat mendeteksi arus hingga 5A dan sinyal arus ini dapat dibaca melalu port Arduino. Sensor arus ACS712 mendeteksi arus yang mengalir ke baterai dari sumber Buck Converter. Sensor arus ini dapat membaca arus kirasaran -5A hingga 5A.

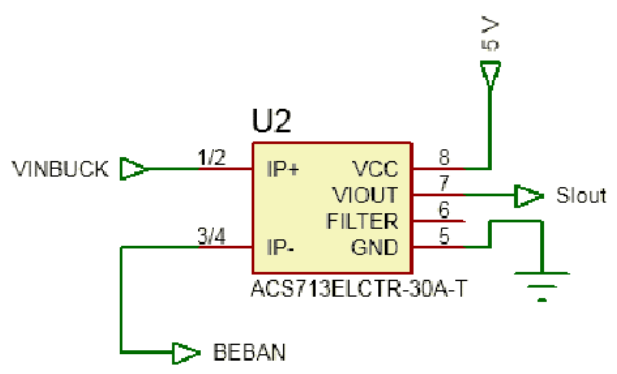

Gambar 3. Rangkaian Sensor Arus 


\subsection{Perancangan Driver Mosfet}

Gambar 4 merupakan driver mosfet berfungsi untuk mengendalikan kinerja Buck Converter yang input-nya berupa sinyal PWM. Sinyal PWM tersebut dikontrol melalui Arduino dengan pengendalian nilai duty cycle yang dihasilkan oleh kontrol PI.

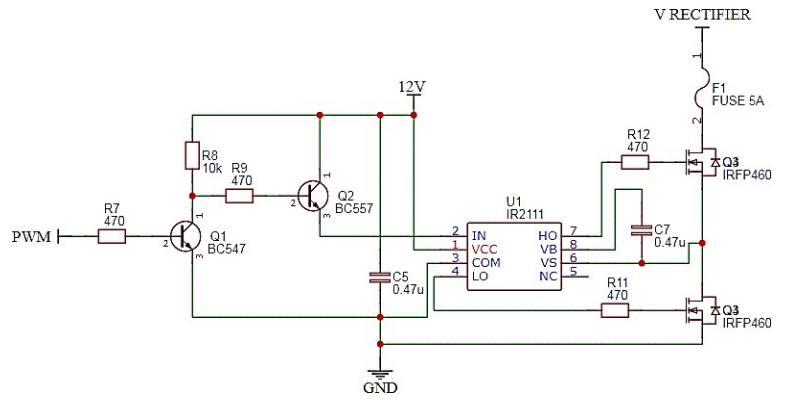

Gambar 4. Rangkaian Driver Mosfet

Sinyal PWM memicu Transistor untuk dikuatkan lalu output HO (High Output) IC IR2111 aktif maka akan memicu mofet Q4 untuk (normaly close) sedangkan jika LO (Low Output) IC R2111 aktif maka akan memicu mosfet Q3 untuk (normaly close). Untuk mengetahui besaran komponen yang digunakan R1, R2 dan R3 pada rangkaian driver mosfet maka dapat menggunakan persamaan yaitu :

Perhitungan Mencari Nilai Hambatan R8

$$
\begin{aligned}
& R 8=\frac{V c c-V c e(s a t)}{I c} \\
& R 8=\frac{12-0,1 \text { volt }}{1,5 A} \\
& R 8=1.190 \Omega
\end{aligned}
$$

Pada rangkaian driver mosfet menggunakan resistor 1,2K Ohm karena terdapat dipasaran.

Perhitungan Mencari Nilai Hambatan R9

$$
\begin{aligned}
R 9 & =\frac{V c c-V b e}{I f} \\
& =\frac{12-0,7}{0,02} \\
& =565 \Omega
\end{aligned}
$$

Pada rangkaian bidirectional converter menggunakan resistor $470 \mathrm{Ohm}$ karena terdapat dipasaran.

Perhitungan Mencari Nilai Hambatan R7

$$
\begin{aligned}
\text { R7 } & =\frac{V_{0} H-V b e}{I f} \\
& =\frac{4.8-0.7}{0.02} \\
& =205 \Omega
\end{aligned}
$$

Pada rangkaian bidirectional converter menggunakan resistor $330 \mathrm{Ohm}$ karena terdapat dipasaran.

Perhitungan Mencari Nilai Hambatan R11

$$
\begin{aligned}
R \mathbf{1 1} & =\frac{V c c-V g s}{I 0-} \\
& =\frac{12-4,0}{0.04} \\
& =200 \Omega
\end{aligned}
$$

Pada rangkaian bidirectional converter menggunakan resistor $470 \mathrm{Ohm}$ karena terdapat dipasaran.

Perhitungan Mencari Nilai Hambatan R12

$$
\begin{array}{r}
R 12=\frac{V c c-V g}{10+} \\
=\frac{12-4.0}{0.02} \\
=400 \Omega
\end{array}
$$

Pada rangkaian bidirectional converter menggunakan resistor $470 \mathrm{Ohm}$ karena terdapat dipasaran.

\subsection{Perancangan Penyearah}

Gambar 5 merupakan perancangan rectifier, rectifier digunakan sebagai penyearah tegangan keluaran generator PMSG 3 phase menjadi tegangan DC dan filter digunakan untuk mengurangi ripple tegangan dari keluaran rectifier.

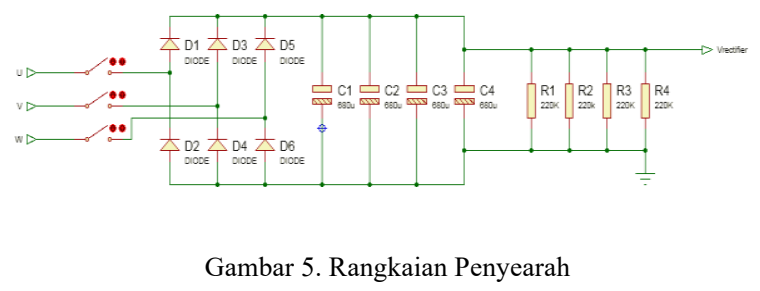

Tegangan AC 3 fasa dari generator melewati diode untuk disearahkan, setelah melewati diode tegangan AC 3 fasa dirubah menjadi tegangan DC yang memiliki banyakripple. Sehingga digunakanlah kapasitor sebagai penyaring filter agar tegangan keluaran dari penyearah yaitu tegangan DC murni. Untuk dapat mengetahui gesaran tegangan $\mathrm{DC}$ yang dihasilkan pada saat $\mathrm{RPM}$ menggunakan persamaan yaitu :

Tegangan Output DC Saat RPM Rendah

$$
\begin{aligned}
& V_{L(\text { PEAK })}=V_{L(R M S) \times \sqrt{ } 2} \\
& V_{L(\text { PEAK })}=18,4 \text { Volt } \\
& V_{S}=\frac{V_{L(R M S) \times \sqrt{ } 2}-}{\sqrt{3}} \\
& V_{S}=10,6 \mathrm{Vdt} \\
& V_{d c}=\left[{ }^{3 \sqrt{3}}-\overline{V_{S}}\right. \\
& V_{d c}=17,5 \mathrm{Vdt}
\end{aligned}
$$

Didapatkan keluaran tegangan DC sebesar 17,5 Volt saat RPM rendah,

Perhitungan Output DC saat RPM Tinggi

Journal of Applied Smart Electrical Network and Systems (JASENS) 


$$
\begin{aligned}
& V_{L(\text { PEAK })}=V_{L(R M S)} \times \sqrt{ } \mathbf{2} \\
& V_{L(\text { PEAK })}=\mathbf{1 1 7}, 3 \text { Volt } \\
& V_{S}=\frac{V_{L(R M S) \times \sqrt{ } 2}-}{\sqrt{3}} \\
& V_{S}=67,7 \text { Volt } \\
& V_{d c}=\left[{ }^{3 \sqrt{ } 3} \frac{-}{\pi} V_{S}\right. \\
& V_{d c}=112 \text { Volt }
\end{aligned}
$$

Didapatkan keluaran tegangan DC sebesar 112 Volt saat $C=\frac{\operatorname{Vout} \times(1-D) 8 \times L}{\times \Delta \operatorname{Vo} \times f}$ RPM tinggi.

\subsection{Perancangan Buck Converter}

Gambar 6 merupakan perancangan Buck Converter, pada perancangan rangkaian Buck Converter dibutuhkan parameter untuk mengetahui nilai dari induktansi, capasitor serta pemilihan tipe mosfet yang digunakan berdasarkan datasheet.

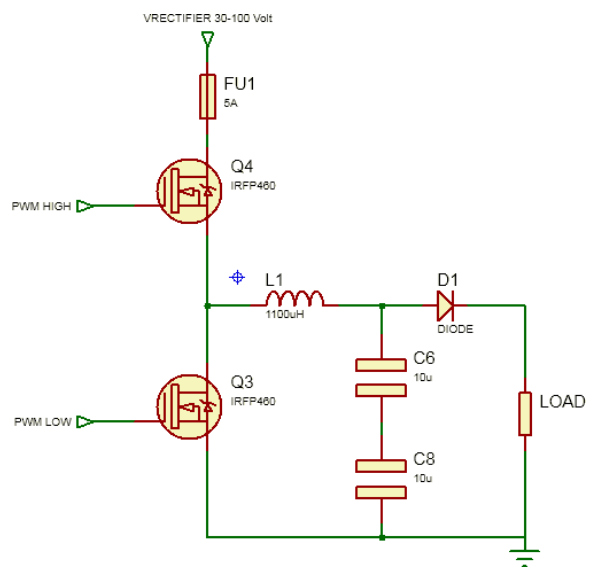

Gambar 6. Rangkaian Buck Converter

Mosfet IRFP460 sebagai switching dan akan aktif jika mendapat input logika high dari IC IR2111 sedangkan tidak aktif apabila mendapat input logika low dari IC IR2111, Inductor sebagai penyimpan arus akan mengalirkan arus melewati kapasitor sebagai pemfilter lalu melewati diode penyearah. Berdasarkan parameter tersebut maka dihitung nilai komponen yang digunakan dengan persamaan yaitu.

\section{Perhitungan Tegangan Ripple}

$$
\begin{aligned}
& \frac{\Delta V_{0}}{V o u t}=\text { ripple } \\
& \frac{\Delta V o}{V o u t}=4 \% \\
& \Delta V o=\frac{54}{100} \\
& \Delta V_{0}=0.54 \text { Volt }
\end{aligned}
$$

Perhitungan Nilai Duty Cycle

$$
\begin{aligned}
& D=\frac{\text { Vout }}{\text { Vin }} \\
& D=0,27
\end{aligned}
$$

Perhitungan Nilai Minimal Induktor

$$
\begin{aligned}
& L=\underline{1} \times(\text { Vin }- \text { Vout }) \times D \times \underline{1} \\
& L=\frac{f}{17,01 \times 103} \\
& L=1,1 \mathrm{mH}
\end{aligned}
$$

Perhitungan Nilai Minimal Kapasitor

$$
\begin{aligned}
& C=\frac{19.71}{3009 \times 103} \\
& C=6 \mu F
\end{aligned}
$$

\subsection{Perancangan Kontrol PI}

Perancangan PI dilakukan dengan menentukan nilai Kp dan $\mathrm{Ki}$ diawal dengan nilai Kp 2.6 dan Ki 5.6 yang digunakan untuk Buck Converter dengan keluaran yang berupa tegangan dengan nilai yang stabil.

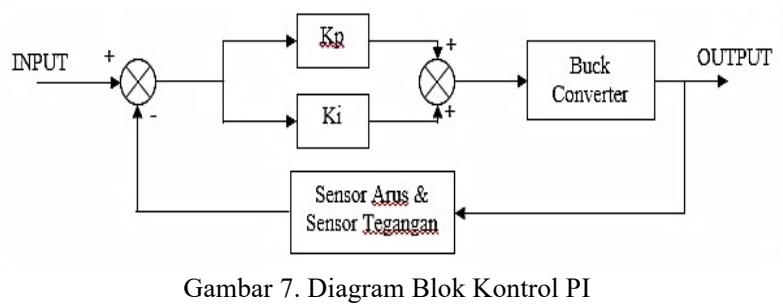

Untuk dapat mengetahui nilai $\mathrm{Kp}$ dan $\mathrm{Ki}$ yaitu dengan cara trial and error memasukkan nilai $\mathrm{Kp}$ dan $\mathrm{Ki}$ serta menggunakan sensor arus dan tegangan sebagai feedback, lalu melihat respon grafik yang dihasilkan hingga mendapatkan hasil dengan error yang kecil.

\subsection{Perancangan NodeMCU IoT}

Perancangan IoT bertujuan mempermudah pemantauan dimanapun. Monitoring ini memanfaatkan platform IoT analitycs yaitu Thingspeak. Gambar 8 merupakan dashboard website thingspeak.

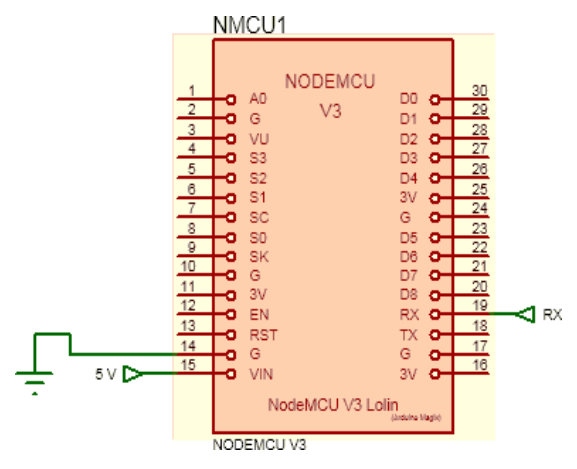

Gambar 8. Rangkaian NodeMCU IoT

\section{Hasil dan Pembahasan}

\subsection{Pengujian Rangkaian Penyearah}

Pada pengujian rangkaian penyearah tiga phase dan filter yang pertama adalah melakukan pengukuran Journal of Applied Smart Electrical Network and Systems (JASENS) 
tegangan dari generator PMSG menggunakan 3.4 Pengujian Buck Konverter

multimeter.

Tabel 1. Tabel Pengujian Rangkain Penyearah

\begin{tabular}{|c|c|c|}
\hline $\begin{array}{c}\text { Kecepatan } \\
\text { PMSG } \\
\text { (RPM) }\end{array}$ & $\begin{array}{c}\text { Tegangan } \\
\text { PMSG } \\
\text { (Vrms) }\end{array}$ & $\begin{array}{c}\text { Tegangan } \\
\text { Rectifier } \\
\text { (Vdc) }\end{array}$ \\
\hline 400 & 26 & 35,7 \\
\hline 600 & 39 & 54 \\
\hline 800 & 51 & 70 \\
\hline 1000 & 64 & 89,4 \\
\hline 1200 & 76 & 106,2 \\
\hline 1400 & 89 & 124 \\
\hline
\end{tabular}

Berdasarkan pengujian penyearah didapatkan apabila putaran turbin atau RPM semakin tinggi maka tegangan akan semakin naik.

\subsection{Pengujian Sensor Tegangan}

Pengujian sensor tegangan dengan cara membandingan antara tampilan LCD dengan alat ukur multimeter untuk mengetahui seberapa besar eror serta kelayakan penggunaan sensor.

Tabel 2. Tabel Pengujian Sensor Tegangan
\begin{tabular}{|c|c|c|}
\hline $\begin{array}{c}\text { Multimeter } \\
\text { (V) }\end{array}$ & $\begin{array}{c}\text { Tampilan } \\
\text { LCD } \\
(\mathrm{V})\end{array}$ & $\begin{array}{c}\text { Error } \\
(\%)\end{array}$ \\
\hline 5 & 5 & 0 \\
\hline 7 & 7,1 & 1,4 \\
\hline 9 & 9,3 & 3,3 \\
\hline 11,8 & 11,8 & 0 \\
\hline 23,6 & 23.4 & 0,8 \\
\hline 31,5 & 30,9 & 1,9 \\
\hline \multicolumn{2}{|c|}{ Rata - rata } & 1,2 \\
\hline
\end{tabular}

Berdasarkan pengujian sensor tegangan didapat error rata-rata pada sensor tegangan sebesar $1,2 \%$, sehingga sensor tegangan layak digunakan.

\subsection{Pengujian Modul Sensor Arus}

Sensor arus yang digunakan merupakan sensor arus ACS712 5A, karena sensor arus ini digunakan untuk mengukur besar arus pada sistem charging baterai yang relatif tidak terlalu besar. Tujuan dari dilakukannya pengujian ini unuk mengetahui besaran error dan kelayakan sensor arus ACS712.

Tabel 3. Tabel Pengujian Modul Sensor Arus

\begin{tabular}{|c|c|c|}
\hline $\begin{array}{c}\text { Multimeter } \\
(\mathrm{V})\end{array}$ & $\begin{array}{c}\text { Tampilan } \\
\text { LCD } \\
(\mathrm{V})\end{array}$ & $\begin{array}{c}\text { Error } \\
(\%)\end{array}$ \\
\hline 0,6 & 0,6 & 0 \\
\hline 0,9 & 0,9 & 0 \\
\hline 1 & 1 & 0 \\
\hline 1,2 & 1,1 & 1,6 \\
\hline 1,4 & 1,3 & 0,7 \\
\hline \multicolumn{2}{|r|}{ Rata - rata } & 0,3 \\
\hline
\end{tabular}

Pada pengujian Sensor Arus ACS712 didapatkan error rata-rata sebesar $0,3 \%$, sehingga sensor arus ACS712 layak digunakan.
Pada pengujian mengamati perubahan output tegangan terhadap perubahan input dengan duty cycle diatur 50\% serta mengamati perubahan output terhadap perubahan duty cycle PWM dengan tegangan input sebesar 40 Volt.

Tabel 4. Tabel Pengujian Buck Converter

\begin{tabular}{|c|c|c|}
\hline $\begin{array}{c}\text { Duty Cycle } \\
(\%)\end{array}$ & $\begin{array}{c}\text { Tegangan } \\
\text { Rectifier } \\
(\mathrm{V})\end{array}$ & $\begin{array}{c}\text { Tegangan } \\
\text { Output } \\
(\mathrm{V})\end{array}$ \\
\hline 10 & 40 & 2,5 \\
\hline 20 & 40 & 6,2 \\
\hline 30 & 40 & 11,8 \\
\hline 40 & 40 & 15,2 \\
\hline 50 & 40 & 19,1 \\
\hline 60 & 40 & 23,4 \\
\hline 70 & 40 & 26,9 \\
\hline 80 & 40 & 30,8 \\
\hline 90 & 40 & 34,7 \\
\hline
\end{tabular}

Dari hasil pengujian rangkaian Buck Converter dapat diketahui bahwa rangkaian Buck Converter bekerja sebagaimana fungsinya, dimana semakin besar nilai duty cycle maka semakin besar nilai tegangan keluaran.

\subsection{Pengujian Kontrol PI}

Pengujian kontrol Pi dilakukan dengan beban baterai 24V dimana keluaran dari Buck Converter yang diinginkan konstan sesuai dengan set point 27 Volt dengan nilai nilai $\mathrm{Kp} 0,6$ dan Pi 2.5 yang berdasarkan trial and error. Nilai $\mathrm{Kp}=0.6, \mathrm{Ki}=2.5$ dengan tegangan input 50 Volt.

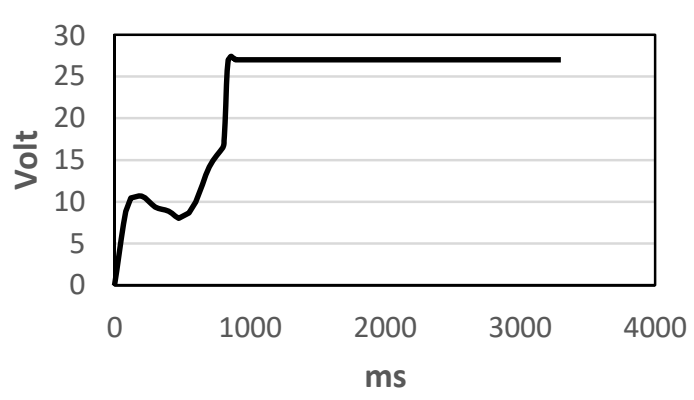

Gambar 9. Respon Tegangan $\mathrm{Kp}=0.6, \mathrm{Ki}=2.5$, dengan Tegangan Input $50 \mathrm{Volt}$

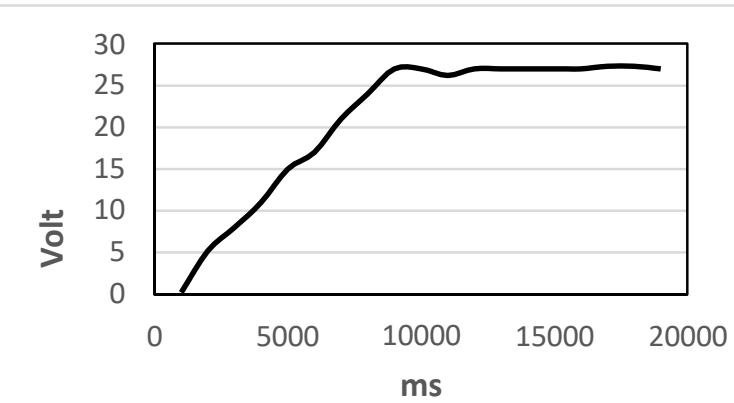

Gambar 10. Respon Tegangan $\mathrm{Kp}=0.6, \mathrm{Ki}=2.5$, dengan Perubahan Tegangan Input

Journal of Applied Smart Electrical Network and Systems (JASENS) 
Hasil dari percobaan dengan nilai $\mathrm{Ki}=2.5$ dan $\mathrm{Kp}=0.6$ Ucapan Terimakasih

maka didapat respon setting time yang lebih cepat serta tidak mengalami osilasi, pada waktu 10 s kecepatan PMSG diperlambat $400 \mathrm{rpm}$ atau tegangan 37.5 Volt terjadi penurunan tegangan output 26,2 dalam selang waktu 1s kemudian kembali normal, hasil yang sama pada saat PMSG dipercepat $650 \mathrm{rpm}$ dengan tegangan 63 Volt maka didapat tegangan output naik 27.3 Volt dalam selang waktu $2 \mathrm{~s}$ kemudian kembali normal atau tidak berosilasi.

\subsection{Pengujian Monitoring IoT}

Pengujian ini, merupakan pengujian sistem monitoring secara keseluruhan pada rangkaian Buck Converter untuk mengetahui apakah rangkaian Buck Converter sudah bisa melakukan pengisian baterai dengan output tegangan secara online.

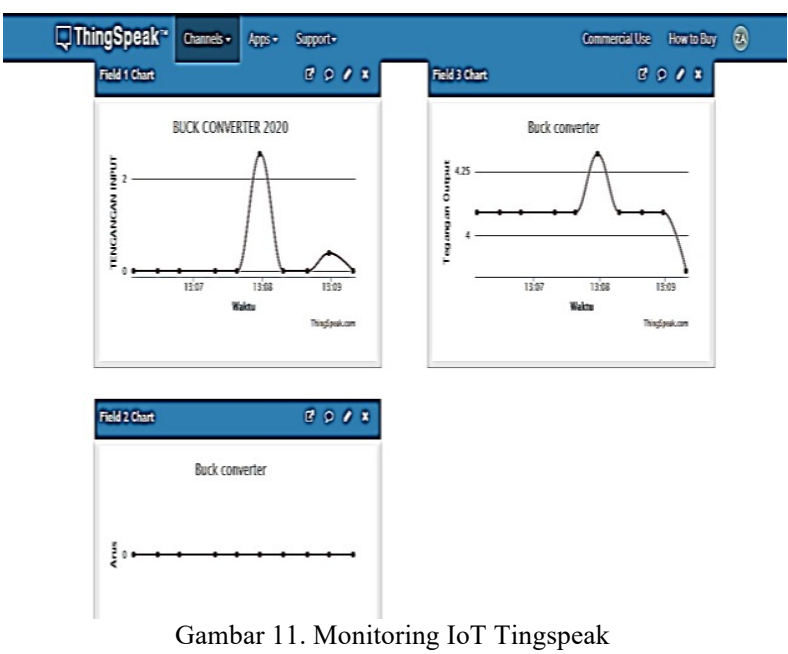

Terima kasih kepada ibu Ratna Ika Putri yang telah meluangkan waktu untuk membantu menyusun artikel ini hingga artikel ini dapat di publikasikan.

\section{Daftar Rujukan}

1] Lukman, A., 2017. Parameterisasi Kendali PID pada Konverter DC/DC Penurun Tegangan dengan Kriteria Domain Waktu dan Efisiensi Daya. Jurnal JPE, 21 (1), pp.87-92.

[2] Akbar, F., 2020. Analisis Variasi Nilai Duty Cycle pada PWM Terhadap Durasi Pengisian Baterai Lithium-Ion dan LithiumPolymer, Jurnal Aplikasi Sains, Informasi, Elektronika dan Komputer, 2 (1), pp.1-10.

3] Nakhoda, Y.I., 2016. Rancangan Bangun Generator Magnet Permanen Untuk Pembangkit Tenaga Listrik Skala Kecil Menggunakan Kinci Angin Savonius Portable, Jurnal Ilmiah SETRUM, 5 (2), pp.71-76.

[4] Husnaini, I., 2017. Komparasi Pengendali PI Dan PID Untuk Tegangan Keluaran Konverter Buck, Jurnal Nasional Teknik Elektro, 6 (3), pp.143-151.

5] Satiawan, I., 2018. Desain Buck Converter Untuk Charging Batere Pada Beban Bervariasi, Jurnal Dielektrika, 5 (1), pp.30-35.

[6] Sodikin, N., 2015. Rancang Bangun Prototipe Emulator Sel Surya Menggunakan Buck Converter Berbasis Arduino, Jurnal Rekayasa dan Teknologi Elektro, 9 (3), pp.171-180.

[7] Antonisfia, Y., 2013. Pengisian Aki Dengan Buck Konverter, Jurnal Elektron, 5 (1), pp.29-33.

[8] Effendy, M., 2019. Perancangan Maximum Power Point Tracking Pada Pembangkit Listrik Tenaga Bayu Menggunakan Four Switch Buck Boost Converter Dengan Metode P\&O-ORN, Jurnal TRANSMISI, 21 (4), pp.103-108.

[9] Jamlay, M., 2014. Dual Feedback Control DC-DC Boost Converter Menggunakan PI Controller, Jurnal Inovasi Teknologi, 4 (2), pp.91-97.

[10] Priananda, C., 2019. Rancang Bangun Konverter Multi Input Buck DC/DC Pada Pembangkit Listrik Hibrida Surya-Angin Untuk Pengisian Baterai, Jurnal ELSAINS, 1 (2), pp.27-36.

Didapatkan hasil dari pengujian monitoring IoT yaitu NodeMCU bekerja sesuai dengan yang diharapkan, yaitu menerima dan mengirimkan data besaran tegangan dan arus ke dashboard thingspeak secara real time.

\section{Kesimpulan}

Berdasarkan hasil pengujian yang telah dilakukan desain buck converter yang terhubung telah dijelaskan pada artikel ini, generator PMSG menghasilkan tengangan AC tiga phasa yang tidak stabil. Untuk menstabilkan tegangan digunakanlah rangkaian Buck Converter, Switching pada rangkaian buck converter menggunakan system half bridge dengan IC IR2110 frekuensi 31,5 $\mathrm{KHz}$. Sehingga buck converter dapat menurunkan tegangan sesuai persamaan Vout $=$ Vin $\mathrm{x}$ D pada range tegangan input 30 -100 Volt dengan duty cyle 10-95\%. Kontrol PI yang digunakan $\mathrm{Kp}=0.6, \mathrm{Ki}=2.5$ untuk mengontrol tegangan output Buck Converter agar sesuai dengan nilai setpoint sebesar 27 Volt. 